\title{
Direct integration of CNT forests on solidly mounted resonators and their influence on device performance
}

\author{
Teona Mirea, Jimena Olivares, Marta Clement, Jesús Sangrador, and Enrique Iborra
}

\begin{abstract}
Carbon nanotubes (CNTs) have been typically employed as active layers in sensors, however their verticallyaligned (forest) morphology has not been fully explored yet. Here we directly integrate CNT forests on AIN-based solidly mounted resonators and study their influence on the performance of the longitudinal and shear mode of operation. Results show that CNT forests induce quality factor degradation and that too tall forests lead to excessive degradation of the frequency response. A trade-off between device performance and surface area increase for better sensing can be found with forests of heights lower than $\sim 10 \mu \mathrm{m}$. Additionally, we show that the shear mode is less degraded than the longitudinal mode and that multi-walled CNTs degrade in less extend the devices.
\end{abstract}

Keywords-carbon nanotube forest; solidly mounted resonator; integration; performance influence.

\section{INTRODUCTION}

Carbon nanotubes (CNTs) have been thoroughly employed as active layers for sensing purposes, particularly in acoustic wave devices [1], [2]. Their high surface area and high chemical affinity make them suitable candidates for boosting the sensor selectivity through functionalization [3]. Typically CNTs have been employed in form of thin films of dispersed nanotubes deposited on the active area of the sensors. Recently, the authors have proposed the direct growth of vertically-aligned (forests) CNTs on AlN-based solidly mounted resonators (SMRs) [4]. Compared to dispersed CNTs, the vertically-aligned morphology offers greater surface areas for detection, selective growth of CNTs by patterning the catalyst, and the possibility of nm-size particle filtering by tuning the distances between the tubes[5], [6].

The direct growth of CNT forests on the top electrodes of SMRs (Fig. 1) required two previous studies: the development of SMRs sustaining high temperatures (CNT growth needs $650^{\circ} \mathrm{C}$ ) [7], and the growth of CNT forests on pure metallic substrates [8]. In this work we discuss the influence of the CNT forests on the final performance of two types of device: (1) single mode devices working on the longitudinal mode, and (2) dual mode devices exciting both the shear and the longitudinal modes. While the longitudinal mode can be employed in gas sensing, the shear mode is needed if the CNTbased SMRs are to be used as biosensors in liquid media [9]. For both applications, the assessment of the forest influence on the device performance is crucial for the sensor optimization.

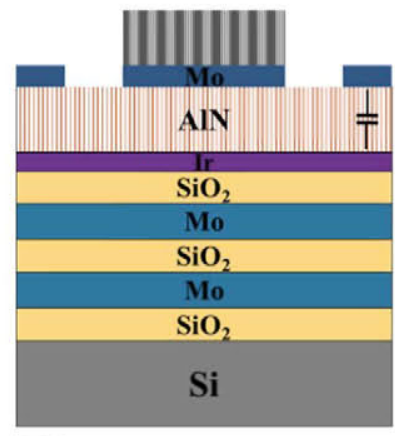

IIII CNT forest

(a)

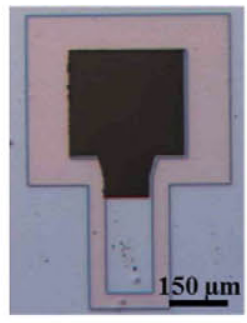

(b)

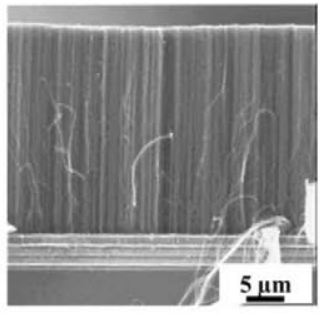

(c)
Fig. 1. SMR with integrated CNT forest on the active area of the top electrode. (a) Sketch, (b) optical top view image, and (c) scanning electron microscopy cross section image.

\section{EXPERIMENTAL}

The influence of CNT forest integration has been studied on the longitudinal and shear modes performances of AlNbased SMRs. These are composed of five altemating layers of $\mathrm{SiO}_{2} / \mathrm{Mo}$ (620/629 nm-thick, respectively) as acoustic reflectors, a $120 \mathrm{~nm}$-thick Ir bottom electrode, a $1 \mu \mathrm{m}$-thick AlN piezoelectric film and a $150 \mathrm{~nm}$-thick Mo top electrode (Fig. 1(a)). For the single mode devices (longitudinal) the AlN layer was deposited with $c$-orientation, while for the dual mode devices (longitudinal and shear) the AlN layer was deposited with tilted grains [10]. CNT forests were grown using low pressure chemical vapor deposition (CVD) [11] and a catalytic system composed of a blocking layer $\left(\mathrm{SiO}_{2}\right.$ or $\left.\mathrm{Al}\right)$ underneath a metallic catalyst (Fe) (Fig. 2). The blocking layer is crucial in this case to avoid bulk diffusion of the catalyst into the metallic top substrate [8]. The thicknesses of the catalytic systems were $50 \mathrm{~nm}$ for the $\mathrm{SiO}_{2}, 12 \mathrm{~nm}$ for the $\mathrm{Al}$, 
and different thicknesses for the $\mathrm{Fe}(1.5 \mathrm{~nm}, 2 \mathrm{~nm}$ and $6 \mathrm{~nm})$. The catalytic bilayers were selectively deposited over the Mo top electrodes by a photolithographic lift-off process (Fig. 1). For the CVD process, $\mathrm{NH}_{3}$ and $\mathrm{C}_{2} \mathrm{H}_{2}$ were used as reducing and carbon source gases, respectively. To be able to grow on metallic substrates, the temperature for the formation of the catalytic nanoparticles (NPs) was lowered $\left(550^{\circ} \mathrm{C} / 600^{\circ} \mathrm{C}\right)[6]$, compared to the one needed for CNT growth $\left(650^{\circ} \mathrm{C}\right)$.

\section{RESULTS AND DISCUSSION}

The electrical characterization of the SMRs before and after CNT forest growth was performed to assess the influence of the forest on the device behavior. As mentioned, both longitudinal and shear modes have been studied. On one hand, for the integration of CNTs on single mode devices, the $\mathrm{Al} / \mathrm{Fe}$ catalytic system was employed. On the other hand, the $\mathrm{SiO}_{2} / \mathrm{Fe}$ catalytic system was the one used for the dual mode devices.

\section{A. Integration on single mode devices}

The CNT forests grown on the top electrodes of SMRs with $c$-oriented AlN were obtained by using the $\mathrm{Al} / \mathrm{Fe}$ catalytic system with thicknesses of $12 \mathrm{~nm}$ and $1.5 \mathrm{~nm}$, respectively (Fig. 2(a)). The obtained forests were composed of single-walled carbon nanotubes (SWCNTs). This is proved by their Raman spectrum (see Fig. 3), where we can observe strong RBM peaks, high $G$ to $D$ ratio, $G$ band split, the presence of $\mathrm{M}$ and iTOLA peaks and the single component of the $2 \mathrm{G}$ peak [12]. The influence of the SWCNT forests on the SMR performance is shown by their electrical characterization in Fig. 4(a). It reveals that the forest induces degradation in both quality factors at resonance $\left(Q_{r}\right)$ and antiresonance $\left(Q_{a}\right)$. The analysis of the SMRs frequency response at the different stages of the CNT growth demonstrates that $Q_{\mathrm{r}}$ degrades owing to the CVD process itself, probably due to the growth of a thin oxide film on the top electrode, while $Q_{a}$ seems to be mainly affected by the presence of the forests. This last is demonstrated by the device electrical measurement after mechanically removing the CNTs which shows almost completely recover of $Q_{a}$ (green curve in Fig. 4(a)).

Further, we also studied the influence of the forest height on the device behavior. By growing forests with different heights we observed that after a certain height value $(\sim 25$ $\mu \mathrm{m})$, the degradation induced starts to be prohibitive, i.e. $Q$ factors below 60 (Fig. 4 (b)).

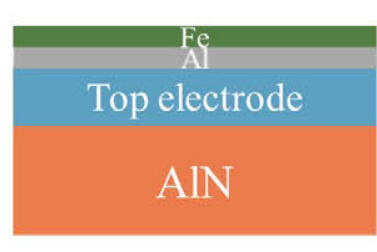

(a)

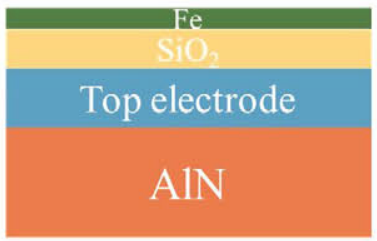

(b)
Fig. 2. Two types of catalytic systems used to grow CNT forest on the metallic top electrodes: (a) Al blocking layer and $\mathrm{Fe}$ catalyst, and (b) $\mathrm{SiO}_{2}$ blocking layer and $\mathrm{Fe}$.

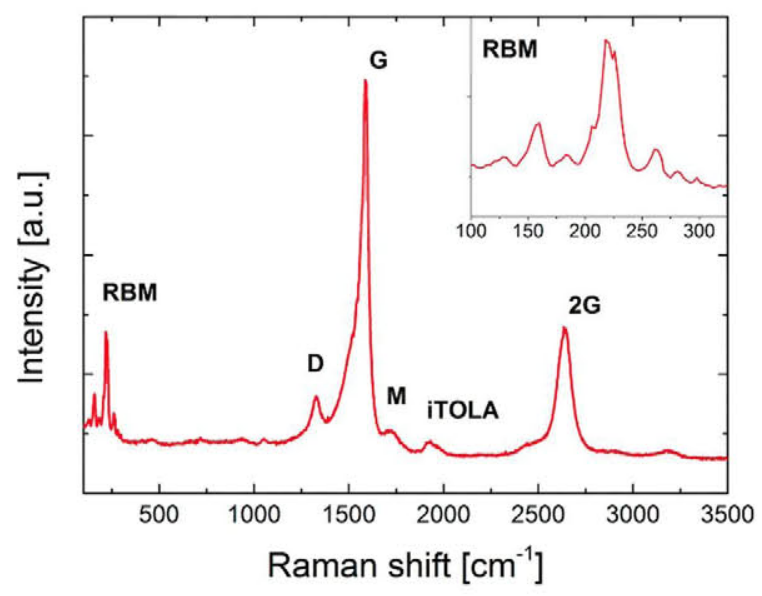

Fig. 3. Raman spectrum of the SWCNT forest grown with $\mathrm{Al} / \mathrm{Fe}$.

We hypothesize that this can be explained by several effects. Firstly, the presence of the CNT forest reduces the wave reflection at the top electrode/air interface compared with that of the uncovered device, since the acoustic impedance of the CNTs is larger than that of the air.
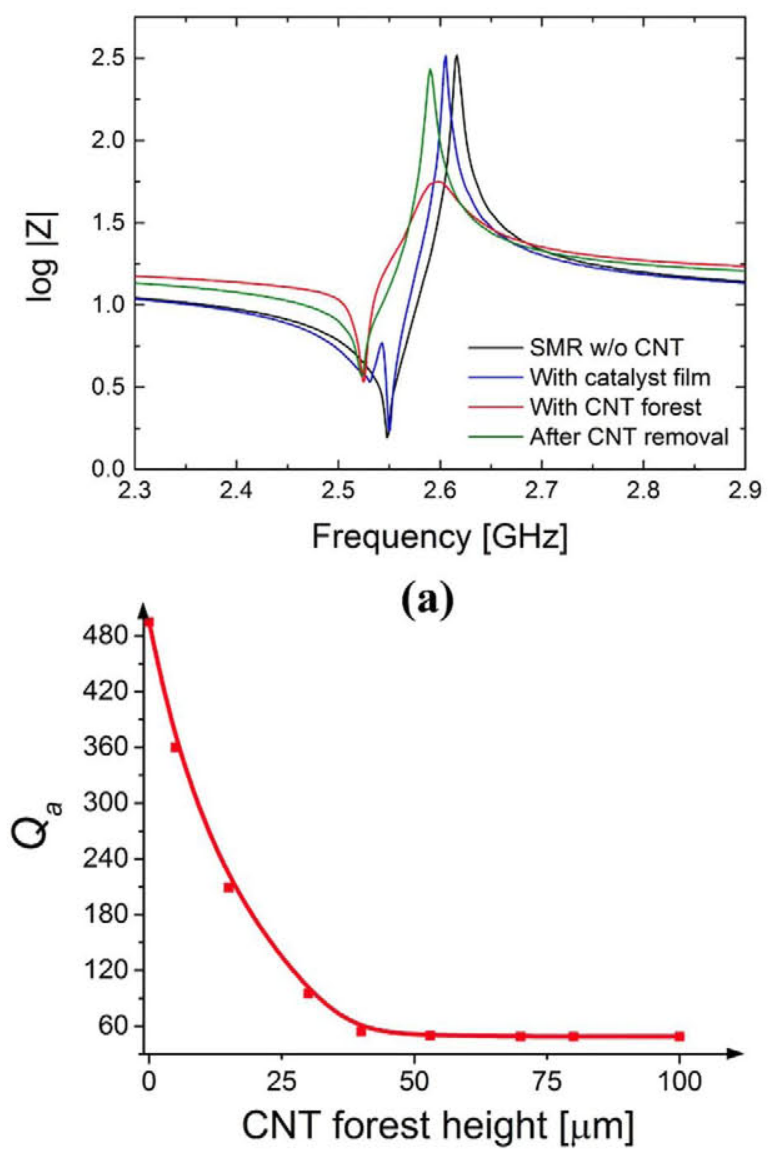

(b)

Fig. 4. SMR longitudinal mode peformance before and after CNT integration. (a) Electrical impedance of SMRs with and without CNTs, and (b) $\mathrm{Q}_{\mathrm{a}}$ degradation with forest height. 
In other words, some energy is radiated to the forest (Fig. 5(a)). Secondly, the reflection at the top CNT forest/air interface is poor due to low acoustic mismatch and loss of coherence owing to the heterogeneity of the forest (Fig. 5(b)). Finally, the CNT forest can be considered as a poroelastic film showing high viscous losses induced by the friction between tubes; the acoustic energy radiated to the forest may be rapidly lost before even reaching the top interface for backward reflection.

\section{$B$. Integration on dual mode devices}

The integration of CNT forests on SMRs with tilted AIN was obtained by using the $\mathrm{SiO}_{2} / \mathrm{Fe}$ catalytic system. In this case, while the thickness of the blocking layer was set at 50 $\mathrm{nm}$, two thickness of Fe were tested, i.e. $2 \mathrm{~nm}$ and $6 \mathrm{~nm}$. By using these two thicknesses for the catalyst different forest morphologies were achieved. More particularly we grew SWCNTs with the lower thickness of $\mathrm{Fe}$ and multi-walled carbon nanotubes (MWCNTs) with the highest thickness of $\mathrm{Fe}$ (see Fig. 6). Both forests with the same height.

The electrical characterization of the dual mode devices, before and after CNTs integration, is presented in Fig. 7 and Table I. The results reveal that:

- Resonant and anti-resonant quality factors are degraded in both shear and longitudinal modes.

- The shear mode is slightly less degraded than the longitudinal mode in both cases, with SWCNTs and MWCNTs.

- MWCNTs induce less degradation than SWCNTs, proved by the higher quality factors after CNTs grown from $6 \mathrm{~nm}$ of $\mathrm{Fe}$.

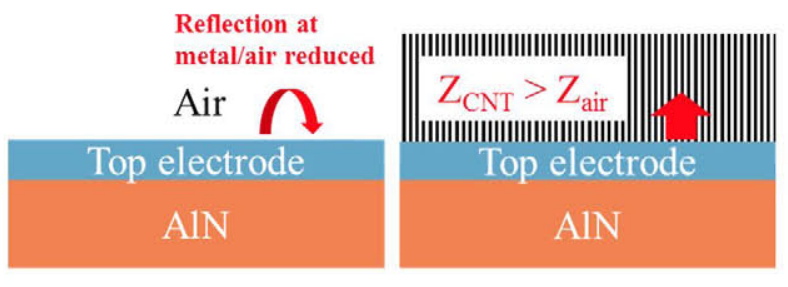

(a)

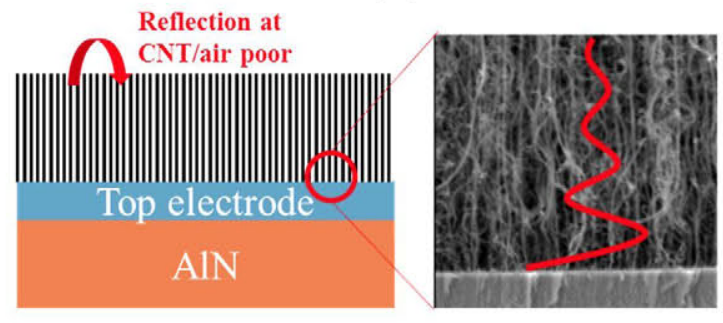

(b)

Fig. 5. Sketches explaining the degradation of $\mathrm{Q}_{\mathrm{a}}$ due to the presence of the CNT forest on the top electrode.

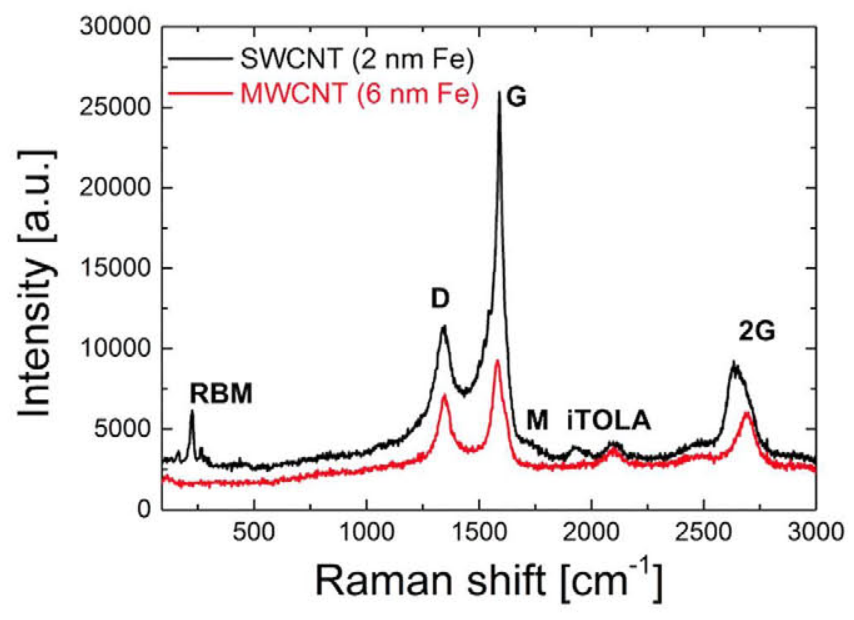

Fig. 6. Raman spectra of the forests obtained with the $\mathrm{SiO}_{2} / \mathrm{Fe}$ catalyst on dual mode devices. SWCNT were grown with $2 \mathrm{~nm}$ of Fe and MWCNT with $6 \mathrm{~nm}$ of $\mathrm{Fe}$.

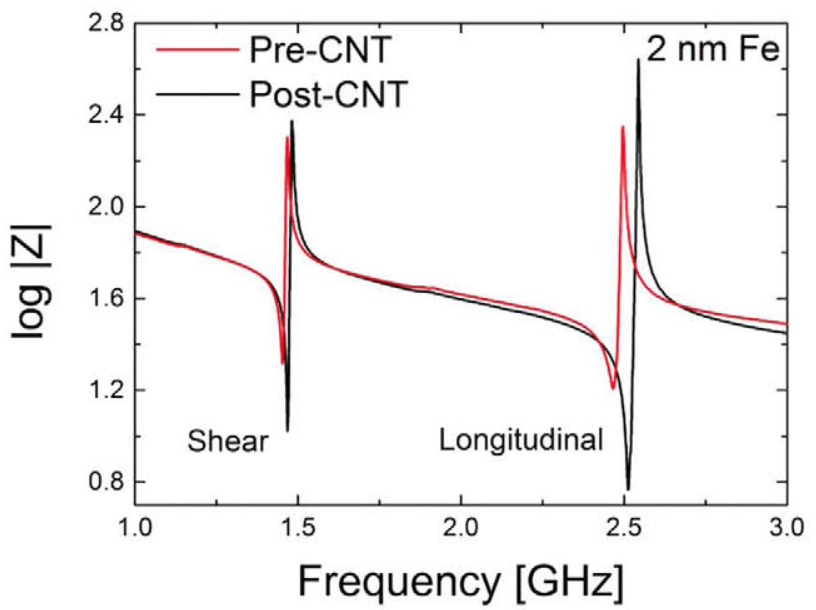

(a)

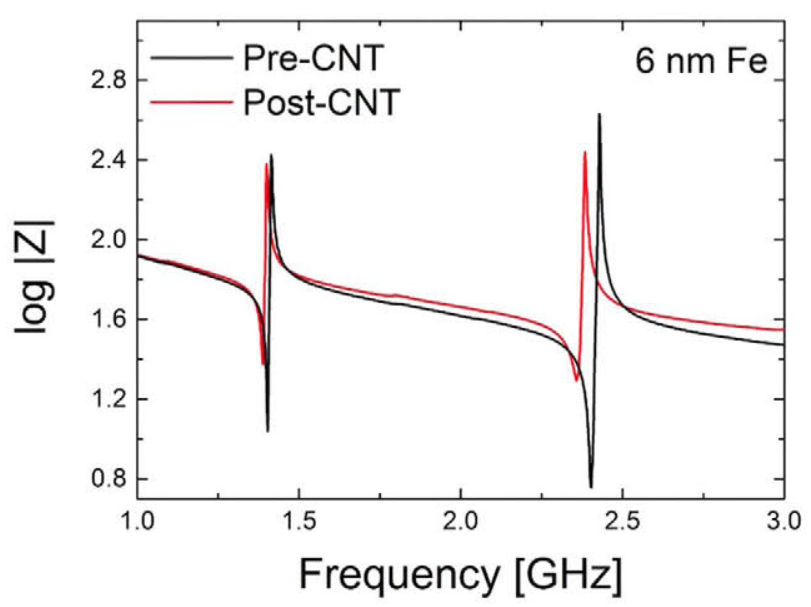

(b)

Fig. 7. Electrical impedances of the dual mode devices (showing the shear and longitudinal modes) before and after CNT integration for (a) $2 \mathrm{~nm} \mathrm{Fe}$ and (b) $6 \mathrm{~nm} \mathrm{Fe}$. 
TABLE I. QUALITY FACTORS OF THE SHEAR AND LONGITUDINAL MODES BEFORE AND AFTER CNT INTEGRATION

\begin{tabular}{|c|c|c|}
\hline \multirow{2}{*}{$\mathbf{~ n m}$} & Before CNT & After CNT \\
\hline \multirow{3}{*}{ Shear } & $\mathrm{Q}_{\mathrm{r}}=268$ & $\mathrm{Q}_{\mathrm{r}}=145$ \\
\cline { 2 - 3 } & $\mathrm{Q}_{\mathrm{a}}=283$ & $\mathrm{Q}_{\mathrm{a}}=195$ \\
\hline \multirow{3}{*}{ Longitudinal } & $\mathrm{Q}_{\mathrm{r}}=230$ & $\mathrm{Q}_{\mathrm{r}}=109$ \\
\cline { 2 - 3 } & $\mathrm{Q}_{\mathrm{a}}=600$ & $\mathrm{Q}_{\mathrm{a}}=297$ \\
\hline \multirow{2}{*}{$\mathbf{6} \mathbf{n m}$} & Before CNT & After CNT \\
\hline \multirow{3}{*}{ Shear } & $\mathrm{Q}_{\mathrm{r}}=311$ & $\mathrm{Q}_{\mathrm{r}}=167$ \\
\cline { 2 - 3 } & $\mathrm{Q}_{\mathrm{a}}=289$ & $\mathrm{Q}_{\mathrm{a}}=252$ \\
\hline \multirow{3}{*}{ Longitudinal } & $\mathrm{Q}_{\mathrm{r}}=280$ & $\mathrm{Q}_{\mathrm{r}}=114$ \\
\cline { 2 - 3 } & $\mathrm{Q}_{\mathrm{a}}=564$ & $\mathrm{Q}_{\mathrm{a}}=341$ \\
\hline
\end{tabular}

\section{CONCLUSIONS}

SMRs with CNT forests directly integrated on their top electrode are envisaged for improving the application of these devices as both gas and biosensors. To optimize the sensors, the influence of the CNT direct integration on the device performance has to be previously known. In this work we investigated the influence of CNT forests on the longitudinal and shear modes operation of the devices, used for their gas and biosensing applications, respectively. By using and $\mathrm{Al} / \mathrm{Fe}$ catalytic system to grow CNT forests on single mode devices (only longitudinal mode) we achieved SWCNTs and showed that they induce strong degradation on the anti-resonant quality factor as the height of the forest is increased. This suggests finding a trade-off between active surface area for sensing and performance degradation. We found that such trade-off could be by using forests with heights below $10 \mu \mathrm{m}$ to prevent the resonator from excessive degradation, which is sufficient to increase the sensing surface area by several orders of magnitude. For the growth of dual mode devices (with shear and longitudinal modes) we used the $\mathrm{SiO}_{2} / \mathrm{Fe}$ catalytic system and studied the influence of two forests morphologies, i.e. SWCNTs and MWCNTs. In dual mode devices we found that, on one hand, the shear mode is less degraded than the longitudinal mode with CNT integration, and, on the other hand, that MWCNTs are preferred since they induce slightly less degradation.

\section{ACKNOWLEDGMENT}

This work was partially supported by Ministerio de Economía y Competitividad del Gobierno de España through project MAT2013-45957-R.

\section{REFERENCES}

[1] M. Penza, P. Aversa, G. Cassano, D. Suriano, W. Wlodarski, M. Benetti, D. Cannatà, F. Di Pietrantonio, and E. Verona, "Thin-film bulk-acoustic-resonator gas sensor functionalized with a nanocomposite Langmuir-Blodgett layer of carbon nanotubes," IEEE Trans. Electron Devices, vol. 55, no. 5, pp. 1237-1243, 2008.
[2] M. Rinaldi, C. Zuniga, N. Sinha, M. Taheri, G. Piazza, S. M. Khamis, and A. T. Johnson, "Gravimetric chemical sensor based on the direct integration of SWNTS on AIN Contour-Mode MEMS resonators," in 2008 IEEE International Frequency Control Symposium, 2008, pp. 443-448.

[3] K. Balasubramanian, M. Burghard, M. Burghard, and K. Balasubramanian, "Chemically Functionalized Carbon Nanotubes," Small, vol. 1, no. 2, pp. 180-192, 2005.

[4] T. Mirea, J. Olivares, M. DeMiguel-Ramos, M. Clement, J. Sangrador, E. Iborra, and S. Esconjauregui, "Carbon nanotube forests as top electrodes for AlN-based electroacoustic resonators," in 2014 IEEE International Ultrasonics Symposium, 2014, pp. 1476-1479.

[5] Y.-T. Yeh, Y. Tang, A. Sebastian, A. Dasgupta, N. Perea-Lopez, I. Albert, H. Lu, M. Terrones, and S.-Y. Zheng, "Tunable and label-free virus enrichment for ultrasensitive virus detection using carbon nanotube arrays," Sci. Adv., vol. 2, no. 10, pp. 1-13, 2016.

[6] A. L. Yost, S. Shahsavari, G. M. Bradwell, R. Polak, F. Fachin, R. E. Cohen, G. H. McKinley, M. Toner, M. F. Rubner, and B. L. Wardle, "Layer-by-layer functionalized nanotube arrays: A versatile microfluidic platform for biodetection," Microsystems Nanoeng., vol. 1, p. 15037, Dec. 2015.

[7] T. Mirea, M. DeMiguel-Ramos, M. Clement, J. Olivares, E. Iborra, V. Yantchev, and I. Katardjiev, "AlN solidly mounted resonators for high temperature applications," in 2014 IEEE International Ultrasonics Symposium, 2014, pp. 1524-1527.

[8] J. Olivares, T. Mirea, B. Díaz-Durán, M. Clement, M. DeMiguelRamos, J. Sangrador, J. de Frutos, and E. Iborra, "Growth of carbon nanotube forests on metallic thin films," Carbon N. Y., vol. 90, pp. 9 15,2015 .

[9] J. Weber, W. M. Albers, J. Tuppurainen, M. Link, R. Gabl, W. Wersing, and M. Schreiter, "Shear mode FBARs as highly sensitive liquid biosensors," Sensors Actuators, A Phys., vol. 128, no. 1, pp. 84 $88,2006$.

[10] M. DeMiguel-Ramos, T. Mirea, M. Clement, J. Olivares, J. Sangrador, and E. Iborra, "Optimized tilted c-axis AlN films for improved operation of shear mode resonators," Thin Solid Films, vol. 590, pp. 219-223, 2015.

[11] J. Robertson, G. Zhong, S. Esconjauregui, C. Zhang, M. Fouquet, and S. Hofmann, "Chemical vapor deposition of carbon nanotube forests," Phys. status solidi, vol. 249, no. 12, pp. 2315-2322, Dec. 2012.

[12] W. Qian, T. Liu, F. Wei, and H. Yuan, "Quantitative Raman characterization of the mixed samples of the single and multi-wall carbon nanotubes," Carbon N. Y., vol. 41, no. 9, pp. 1851-1854, 2003. 